\title{
The perspective of media of city tourism image shaping
}

\author{
Hua Jin ${ }^{1, a}$ \\ ${ }^{1}$ School of Chang chun Sci-Tech University, Chang Chun 130000, China. \\ 57615211@qq.com
}

Keywords: Tourist city, Image creation, The media, Strategy.

\begin{abstract}
Now the tourism market has developed rapidly, and tourism city image creation is also an important content of urban development. In modern society, the image of tourist city important internal relation between shape and media, both are inseparable. Tourist city should take positive and effective media strategy to give shape to the self-image and dissemination, to promote the development of tourism.
\end{abstract}

\section{Introduction}

The image of tourist city can be regarded as a modern tourist city extremely valuable intangible assets.Its image and communication in the tourist city of society, economy, culture of various development is of great significance. The so-called "city image" is mainly refers to people for subjective impression of a city, and impression to a certain extent from the media to the influence of their psychological and other factors work together. So the shaping and development of the tourism image of the city is closely related to the role of the media. Under the perspective of media, can see that the media's own function with the image of the city has a multidimensional influence, including the shape, and even the development of image.The future orientation has a very important role, can say social media is the tourist city image shaping and development of the booster. Understand the media under the perspective of tourism city image for the development of the tourist city has important social and economic value.

\section{The relationship between media and tourism city image shaping}

Many public mainly through social media and communication structure of publicity to understand the basic situation of the tourist city, the tourist city is also through the mass media through a variety of forms will spread its image. "Tourist city" itself is a words with the concept of social communication media, it is all sorts of media design some representative culture concepts. The popularity of mass media for tourism city and to a certain extent promote the concept of tourism consumption, can be said to be the media shape the tourism city and city economy, make the cultural values into the economic value of the city. Relationship between the media and the image of tourist city embodied in the following aspects:

\subsection{The media is an important carrier of city tourism image shaping}

Mass media through a variety of different media in the spread of the exchange of information and social activities is not only a virtual culture dissemination activities, but also to a certain extent and affect other aspects of the society, all kinds of social activities are inseparable. Media culture is the soul of tourism culture and tourism economy and the foundation, the media in all aspects of the tourist city development is of great importance to carrying role and influence, also can promote the development of other tourist city hand in hand. The spread of the media through the media function for tourism city tourism development direction. The mass media information carrier is also a tourist city need to objective conditions, the establishment and spread of city tourism image must be with the help of the media means and the media, to get the information of the receiver is tourists understand, at the same time, the media also to each tourist city and feedback, is helpful to adjust tourism policies and key tourist cities, so as to make the image more convenient.

\subsection{Media is the important means to improve and perfect of city tourism image}

The function of the mass media dissemination of information is advantageous to the tourist city 
culture communication and the improvement of aesthetic value, through the media images, language, text multimedia means such as tourist city of detailed concept of the cultural connotation and attitude to life is passed to the potential tourists, for modern life trend has a guiding role, also for tourist city art, culture, ideological cultivation and quality enhancement has the practical significance, for important role in the tourist city their aesthetic ability. The spread of the mass media to tourist city comprehensive conditions of reaction,let the potential visitors to understand the region's tourism industry present situation, for cultural and economic has a promoting effect. The mass media also is advantageous to the urban environment beautification. Propaganda to make tourism city in image creation is more attention to the construction of environment.

\subsection{Media is the supervisors of city tourism image shaping}

Media for tourism city image shaping process of public opinion supervision. According to the famous media experts, by the transmission of the social function and the structure of the media in the process of city image has the greatly strengthened the role of monitoring and early warning, to the influence of city tourism image shaping and development of threat or opportunity arises when a warning is given, the mass media is the tourist city of monitor, moment to supervise its social, economic, environment and so on the change of the situation, and to timely information. Media surveillance or warning function contributes to the change of the tourist city of according to oneself circumstance, make proper adjustment or change rapidly, especially the image of tourism city, there are signs of damage or crisis is helpful for the government, mass media information society, the visitors found it in time, and will do no loss, to minimize losses or other media watchdog role, help tourist city management agencies to improve the public service consciousness, improve the quality of service management, thereby increasing the attractive tourist city.

\subsection{The media is a tourist city image creation inspiration}

Mass media can provide feasible for the image of tourist city shape issue, according to the American media experts MaiKaiM and 1972 media issues set up the concept, the mass media for city tourism image shaping give rise to the issue of positive support, allow them to think in terms of different approaches and ideas of the tourism city image shaping. On this basis, the media for tourism city image provides a complete consensus building mechanism, the concept of local government or agencies, attitude and behavior have a positive impact, from the point of view of tourism city image creation process, if the media can image in the shape of positive issue orsuggestions involved in the construction of tourist city, to take a variety of means. for example, discussions, debates, television reports, newspaper headlines, a certain extent to the tourist city's point of view, position or government activities have a positive impact, to the establishment and improvement of the urban image provides new train of thought and ways.

\section{Specific media strategy of city tourism image shaping}

Tourism city image and improve cannot leave a positive role in media communication, positive and effective media strategy can greatly improve the image of tourism city and value. Media have for the tourism industry and tourism city you need must be in a reasonable strategy to play its proper role.

\subsection{Tourism city should be actively integrate resources}

Tourism city should be actively integrate resources include government and media organizations, a comprehensive image creation, transmission, improve and perfect the system of planning. This tourist city needs not only the efforts of the government institutions, it should be need more institutions, many organizations cooperation mechanism. In the tourist city, set up by the tourism management institutions can be combined with actual situation, the government propaganda and media agencies from personnel of course of city image creation of comprehensive institutions, actively attract the media professionals to participate in. On the basis of fully utilize resources, various communication to carry out the image of planning as a whole. In chongqing, for example: the local government and media organizations to the region's tourism as a pillar industry to develop, the tourism market of chongqing and image shaping, the implementation of the "big project" of city tourism image strategy, and establish the chongqing tourism holding group and investment 
enterprises, set up the tourism investment group and holding group, implements the government institutions and business institutions, media organizations cooperation.

\subsection{City tourism image shaping and propaganda}

Tourism city needs a high quality image of the mold and propaganda, high investment, influential media work or work to promote, need special funding base of mass media. Most of the tourist city tourism image of the mold is not perfect and mature stage, the lack of enough propaganda and work. In view of the actual situation of tourist city tourism administrative departments should actively into special propaganda media, to the development of special high-quality propaganda work and creation, increase tourism city image propaganda and attractive. Now a lot of tourist city relying on local natural landscape, for example, to participate in the creation of the film and television works, such as yongzhou region of chongqing's tourist attractions is involved in "house of flying daggers", zhangjiajie is involved in American director Cameron's "avatar", these films made very good economic and social benefits, local tourism resources show in front of the movie, and even the world audience, it has very positive meaning for tourism city image.

\subsection{Set up the subject consciousness in the media publicity}

Tourism city image building need to set up the subject consciousness in the media publicity. Of tourism city image in technology and means, make full use of the media should pay attention to excavate the thematic focus of the city or the selling point. In the mass media must first to the characteristics of the tourist city with a strong general or inductive, will the tourist city's unique natural scenery and the social and historical cultural tourism resources combined together. What is more important for the tourism city image propaganda should be with a strong identification and personality characteristics, image and other tourist cities in the region can be quickly, such as: hot pot city, chongqing.

\section{Summary}

With the development of the tourism market gradually, the market competition increasingly incentive, this would require the tourist city of its own image of the shape to be more serious, also want to take more appropriate media communication strategy. $\mathrm{n}$ addition, in the media technology on the basis of city image, is a system engineering, need government agencies, media and even marketing team actively cooperate with, increasing investment, sets up the theme of tourist publicity, in multimedia areas and emerging media, to science, reasonable shape the image of tourism city.

\section{Acknowledgement}

This research was financially supported by the "Much starker choices-and graver consequences-in" social science research of jilin province department of education(Grant NO. [2016]588).

\section{References}

[1] Song Zhao ju, City tourism image shaping: The theory and the case of Qingdao ,The Qingdao university master degree thesis, vol.17, pp. 292-311, 2013.

[2] M. Ben-Daya, M. Darwis, and K. Ertogral, The joint economic lot sizing problem: Review and extensions, European Journal of Operational Research, vol. 185, pp. 726-742, 2008.

[3] L. Lu, A one-vendor multi-buyer integrated inventory model, European Journal of Operational Research, vol. 81, pp. 312-323, 1995. 